\title{
Cardiac rehabilitation in Nigeria and its challenges
}

\author{
Edafe E Auchi ${ }^{1 *}$, Ajayi Adebayo ${ }^{1}$ and Stanley $\mathrm{CN}^{2}$ \\ ${ }^{1}$ Department of Cardiology Unit, Bayelsa Specialist Hospital, Yenagoa, Nigeria \\ ${ }^{2}$ Department of Pharmaceutical Microbiology, University of Port Harcourt, Nigeria
}

\begin{abstract}
Cardiac Rehabilitation (CR) is a goal targeted program designed for the patient living with cardiovascular disease such as myocardial infarction, heart failure, valvular heart disease to have maximum benefits of self-depended and alleviate the disease condition. It improves morbidity and reduces mortality. In this review, our objective is to discuss the challenges of cardiac rehabilitation in Nigeria.
\end{abstract}

\section{Introduction}

Before 1950, strict bed rest was prescribed for patient with myocardial infarction. Exercise such as staircase claiming was discouraged for years [1]. As at 1950, coronary artery disease was not the problem of Sub-Saharan Africa [2]. Africa was engulfed with infectious disease such as bacterial, viral, protozoa and fungal infection [2]. Cardiac rehabilitation is a program offered to patients diagnosed with heart disease.

Cardiac rehabilitation refers to the sum of all the activities required to keep the cardiac patient best possible physical, mental, and social wellbeing that enable take part in the community [3]. It is the coordinated use of medical, psychological, educational vocation and physical measures to return and keep the cardiac patient to active and satisfactory lifestyle [3]. It is a multidisciplinary team of health professionals encouraged to support and achieve and maintain optimal physical and psychosocial health of the cardiac patient [4]. The multidisciplinary include the health care professionals, patient partner, family and community members [4]. Cardiac rehabilitation is an accepted form of management for people with cardiac disease. Initially, rehabilitation was offered mainly to people recovering from a myocardial infarction (MI), but now encompasses a wide range of cardiac diseases [2].

The aim of cardiac rehabilitation is to minimize the physiological and psychological impact of cardiovascular disease, reduce the risk factors for sudden death, control cardiac symptoms, stabilize or reverse the atherosclerotic process, and enhance the psychosocial and vocational status of selected patients and promote an active life style [5].

\section{Multidisciplinary approach}

Multidisciplinary approach is needed to practice effective cardiac rehabilitation. The multidisciplinary team members include cardiologist/physician and co-coordinator to lead cardiac rehabilitation, clinical nurse specialist, physiotherapist, clinical nutritionist/dietitian, occupational therapist, pharmacist, psychologist, smoking cessation counselor/nurse, social worker, vocational counselor and clerical administration [6].

It is important that all cardiac rehabilitation staff have adequate training, qualifications, skills, and competencies to practice. These professional skills are required for effective use and benefit of the cardiac patient. The cardiac rehabilitation team should always work together with periodic auditing of their work ethics for maximum patient benefit $[7,8]$.

\section{Core components of cardiac rehabilitation}

The components of cardiac rehabilitation include

-Health education and behavioral change

-Lifestyle risk factor management; exercise, diet, smoking cessation

-Psychosocial health

-Medical risk factor management

-Cardioprotective therapies

-Long term management

-Audit and evaluation

The delivery of these core components will require expertise from a wide range of professionals which made up the multispecialty (Figure $1)$.

\section{Indication}

Cardiac rehabilitation may be offered to all cardiac patients who would benefit from it [7]. It is mainly prescribed to patients with ischemic heart disease, with myocardial infarction, after coronary angioplasty, after coronary-aortic by-pass graft surgery and to patients with chronic heart failure. CR begins as soon as possible in intensive care units, only if the patient is in stable medical condition. Intensity of rehabilitation depends on the patient's condition and complications in the acute phase of disease $[8,9]$.

${ }^{\star}$ Correspondence to: Edafe Emmanuel Auchi, Department of Cardiology Unit, Bayelsa Specialist Hospital, Yenagoa, Nigeria, E-mail: dremmanueledafe@gmail.com

Key words: cardiac rehabilitation, Nigeria, challenges

Received: February 13, 2020; Accepted: February 21, 2020; Published: February 28,2020 


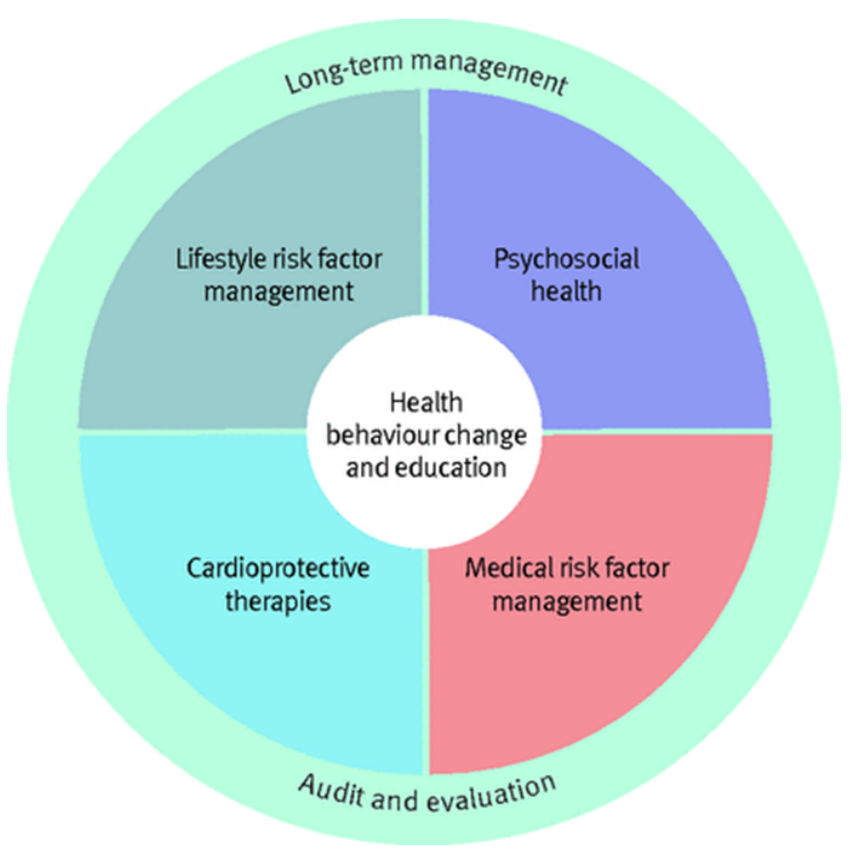

Figure 1. Core components of cardiac rehabilitation

Goals of cardiac rehabilitation: The main goal of cardiac rehabilitation is to promote secondary prevention and to enhance quality of life as much as possible among cardiac patients [4].

\section{Individual risk assessment}

CR can be tailored to meet individual needs. This will require the assessment and evaluation of the cardiovascular risk factor profile of the patient. It should be combined with ongoing assessment and reassessment throughout and upon completion of the program [4]. Validated risk factors by measuring the co-morbidities. Others evaluated parameters include family support social history and occupation $[10,11]$. Cardiac rehabilitation is offered to all cardiac patients that need it. Age is not a barrier to cardiac rehabilitation participation [4].

\section{Phases of cardiac rehabilitation}

Cardiac rehabilitation has four phases. The term phase is used to denote the various time frames following a cardiac event. The secondary prevention component of $\mathrm{CR}$ requires delivery of exercise training, education, and counseling, risk factor intervention and follow up [10]. All referrals the CR UNIT should include the following:

-Patients name, age, address and contact number

-Type of cardiac event and date of event

-Cardiac history, complications and medications

-Reason for referral

-Referring person's name and contact number, date of request

-Clinically relevant information - results of exercise stress test, echo, fasting lipid profile and fasting glucose profile [1].

Phase I: In-hospital patient period.

This is the acute phase. This start when the patient is still in the hospital before discharge. It may take 2-5 days or more. The team members should visit the patient. The team members should give support to the family and patient. The team should evaluate the community that will integrate the patient [4].
The team asses the mobility and its effects on the cardiovascular system, providing the explanation to the patient [4]. Prescribe safe exercises to help improve patient mobility and cardiac fitness. Help patient maintain sternal precautions if there was open-heart surgery and address any risk factors that may lead to cardiac events $[1,8]$. Prescription of an appropriate assistive device to aid walking. Work with the family and community to provide education and integration with optimal life self-support. Discussion of lifestyle modifications of personal risk factors and help provide an individual plan to support these lifestyle changes.

Plan a personal discharge activity program and encourage the patient to adhere to it with commencement daily walks. Inform patients regarding phases II, III and IV programs if available and encourage their attendance. Activity levels should be progressed using a staged approach which should be based on the patient's medical condition. Patient should be closely monitored for any signs of cardiac decompensation. Assess the psychological wellbeing of the patient with aim to address anxiety or depression.

\section{Phase II: Post-discharge period}

This is also called sub-acute phase. It begins when the patient leaves hospital. It continues in the outpatient department. Phase two of cardiac rehabilitation usually lasts from three to six weeks. It involves continued monitoring of your cardiac responses to exercise and activity [7]. The patient is encouraged to continue exercise as much as can be tolerated. There is continue support to the family and promotion of continuing adherence to lifestyle recommendations [8]. Support and education can be provided through, home visits, phone calls, outpatient reviews and provision of educational classes [12].

\section{Phase III: Intensive outpatient therapy}

Phase three of cardiac rehabilitation is more of independent and group exercise [13]. There is monitoring of the heart rate and symptomatic response to exercise. The team may be present during this phase to assess patient efforts. As the patient becomes more independent during phase three of cardiac rehabilitation, the team could help tailor a program of exercises, including flexibility, strengthening, and aerobic exercise.

\section{Phase IV: Independent ongoing conditioning}

The final phase of cardiac rehabilitation is an independent and ongoing conditioning [7]. If the patient fully participated in the previous three phases, there should be good knowledge about specific condition, risk factors, and strategies to maintain optimal health.

This stage involves independent exercise and conditioning. These are essential to maintaining optimal health and preventing possible future cardiac problems. While phase four is an independent maintenance phase, the team should always be available to help make changes if necessary, to achieve good physical wellbeing. Exercise should be based on clinical status, risk stratification, future needs and family education. Counseling and behavior modification with cessation of smoking and vocational counseling [4].

\section{Activities of cardiac rehabilitation}

\section{This include the following:}

Medical evaluation: The health team will generally perform an initial evaluation to check your physical abilities, medical limitations and other conditions that the patient have. This evaluation is done from time to time to track the progress the patient has made. 
During your evaluation, team may look at your risk factors for heart complications, particularly during exercise. This help the team tailor a cardiac rehabilitation program to meet the individual needs, safety and effectiveness.

Physical activity: Cardiac rehabilitation can improve the cardiovascular fitness through physical activity. The health team will likely suggest low impact activities that have a lower risk of injury, such as walking, cycling, rowing, jogging and other activities. The patient usually exercises at least three times a week. The team will likely teach the patient proper exercise techniques, such as warming up and cooling down.

Patient may do muscle-strengthening exercises, such as lifting weights or other resistance training exercises, two or three times a week to increase your muscular fitness.

Lifestyle education: Patient will usually receive support and education on making healthy lifestyle changes, such as eating a hearthealthy diet, exercising regularly, maintaining a healthy weight, quitting smoking, psychological and behavioral changes. This also will reduce high cholesterol and blood pressure. Patient also need to continue taking any medications you've been prescribed by the doctor

Support: Adjustment to a serious health problem often takes time. Patient may feel depressed or anxious, lose touch with the social support system, or must stop working for several weeks. The health team should always address depression and anxiety even before clinical manifestation. Sometime antidepressants may be needed. New skills may be thought to the patient in Vocational or occupational therapy.

\section{What are the risks of cardiac rehabilitation?}

Patients with unstable angina, uncontrolled ventricular arrhythmia and severe heart failure (NYHA level 3 or 4 , ejection fraction <35\%) are considered high risk, with risk stratification conducted by an experienced clinician before they engage in the exercise component of cardiac rehabilitation [8]. However, recent Cochrane review found no evidence to suggest that exercise training program cause harm in terms of an increase in the risk of all cause death in either the short or longer term, in patients with stable chronic heart failure (NYHA level 1-3) [14-17].

Access to cardiac rehabilitation: Patients, who have difficulty accessing the center based cardiac rehabilitation or who does not want group sessions, may have home based cardiac rehabilitation [18]. It has been shown to be just as effective as center-based programs $[19,20]$.

\section{Barriers to cardiac rehabilitation participation}

This include the following:

-Poor referral rates, especially for; Women, ethnic minority groups, elderly persons, persons living in rural setting, low socio-economic class

-Poor patient adherence

-Lack of endorsement by a Doctor

-Obesity

-Smoking cigarette

-Depression

-Transport problems

-Lack of leave from work to attend center-based sessions.

\section{Beneficiaries of cardiac rehabilitation include:}

- Patients with acute coronary syndrome (STEMI, NSTEMI, UA)

- Patients undergoing reperfusion (CABG, PCI)

- Patients with newly diagnosed chronic heart failure and chronic heart failure with a step change in clinical presentation.

- Patients with ventricular assist device and heart transplant

- Recipients of ICDs or cardiac resynchronization therapy for reasons other than ACS and heart failure.

- Patients with valve replacements for reasons other than ACS and heart failure

- Patients with confirmed exertional angina

(According to NICE, Department of health, BACPR, and European guidelines) [21].

\section{Challenges of cardiac rehabilitation in Nigeria}

These challenges could be grouped in to human and non-human resources. Cardiac rehabilitation as a specialty of cardiology is still rudimentary in Nigeria. It is not welled practice in the country. The human resources challenges include lack of focal personal on cardiac rehabilitation. All the specialties mentioned above may be present, but the in-depth practical knowledge of CR to benefit the patient may not be fully be actualized. There are physiotherapists but not training not specifically on CR. We run outpatient clinic and discus with patient as they come. But many lack the ability of running a setup of cardiac rehabilitation.

The patient factors in our challenges are late presentation, lack of commitment to appointment and non-adherence to medication and the exercise prescribed. Many hospitals in Nigeria do lack of access to the equipment needed for CR. There is no funding in this regard. Many patients cannot afford the payment for CR. There is low level of public awareness to advocate for receiving for cardiac patients to receive $\mathrm{CR}$.

\section{Recommendations}

The government of the country has a lot to do in making healthcare affordable in-patient management. There should be a policy to by government to enroll all cardiac patients for CR program. The government at federal, state and local government should send professionals for training in CR. The program should embed in the National Health Scheme for cardiac patients to assess it. Individuals and Hospital and the communities should also made adequate effort to ensure this program is in their territory.

\section{Conclusion}

Cardiac Rehabilitation is a life enhancing program. But it uses in Nigeria still limited in many centers due to lack of human and material resources.

\section{Financial support and sponsorship}

Nil.

\section{Conflicts of interest}

There are no conflicts of interest. 


\section{References}

1. Babu AS, Noone MS, Haneef M, Naryanan SM (2010) Protocol-Guided Phase-1 Cardiac Rehabilitation in Patients with ST-Elevation Myocardial Infarction in A Rural Hospital. Heart Views 11: 52-56. [Crossref]

2. Onen CL (2013) Epidemiology of ischaemic heart disease in sub-Saharan Africa. Cardiovasc J Afr 24: 34-42. [Crossref]

3. Mampuya WM (2012) Cardiac rehabilitation past, present and future: an overview. Cardiovasc Diagn Ther 2: 38-49. [Crossref]

4. Scottish Intercollegiate Guidelines Network (2002) Cardiac rehabilitation: a national clinical guideline.

5. Balady GJ, Williams MA, Ades PA, Bittner V, Comoss P, et al. (2007) Core components of cardiac rehabilitation/secondary prevention programs: 2007 update: a scientific statement from the American Heart Association Exercise, Cardiac Rehabilitation, and Prevention Committee, the Council on Clinical Cardiology; the Councils on Cardiovascular Nursing, Epidemiology and Prevention, and Nutrition, Physical Activity, and Metabolism; and the American Association of Cardiovascular and Pulmonary Rehabilitation. Circulation 115: 2675-2682. [Crossref]

6. Robertson L (2006) American Association of Cardiovascular and Pulmonary Rehabilitation. Cardiac Rehabilitation Resource Manual. Champaign: Human Kinetics.

7. Pryor JA, Prasad SA (2008) Physiotherapy for Respiratory and Cardiac Problems. Philadelphia: Elsevier.

8. Buckley JP, Furze G, Doherty P, Speck L, Connolly S, et al. (2012) BACPR scientific statement: British standards and core components for cardiovascular disease prevention and rehabilitation. Heart 99 .

9. Dalal HM, Doherty P, Taylor RS (2015) Cardiac rehabilitation. BMJ 351: 500.

10. Robertson L (2006) American Association of Cardiovascular and Pulmonary Rehabilitation. Cardiac Rehabilitation Resource Manual. Champaign: Human Kinetics.

11. Williams Wilkins L (2000) ACSM's Guidelines for Exercise Testing and Prescription. American College of Sports Medicine. Philadelphia.
12. de Macedo RM, Faria-Neto JR, Costantini CO, Casali D, Muller AP, et al. (2011) Phase I of cardiac rehabilitation: A new challenge for evidence-based physiotherapy. World $J$ Cardiol 3: 248-255. [Crossref]

13. McMahon SR, Ades PA, Thompson PD (2017) The role of cardiac rehabilitation in patients with heart disease. Trends Cardiovasc Med 27: 420-425. [Crossref]

14. Piepoli MF, Corra U, Adamopoulos S, Benzer W, Bjarnason-Wehrens B, et al. (2014) Secondary prevention in the clinical management of patients with cardiovascular diseases. Core components, standards and outcome measures for referral and delivery: a policy statement from the cardiac rehabilitation section of the European Association for Cardiovascular Prevention \& Rehabilitation. Endorsed by the Committee for Practice Guidelines of the European Society of Cardiology. Eur J Prev Cardiol 21: 664-681. [Crossref]

15. NICE (2010) National Institute for Health and Care Excellence. Clinical guidance 94.

16. Mant J, Al-Mohammad A, Swain S, Laramee P (2011) Management of chronic heart failure in adults: synopsis of the National Institute for Health and clinical excellence guideline. Annals of internal medicine 155:252-259. [Crossref]

17. Long L, Mordi IR, Bridges C, Sagar VA, Davies EJ, et al. (2019) Exercise-based cardiac rehabilitation for adults with heart failure. Cochrane Database Syst Rev 1: CD003331. [Crossref]

18. Dalal HM, Evans PH (2003) Achieving national service framework standards for cardiac rehabilitation and secondary prevention. $B M J 326: 481-484$. [Crossref]

19. Dalal HM, Evans PH, Campbell JL, Taylor RS, Watt A, et al. (2007) Home-based versus hospital-based rehabilitation after myocardial infarction: A randomized trial with preference arms--Cornwall Heart Attack Rehabilitation Management Study (CHARMS). Int J Cardiol 119: 202-211. [Crossref]

20. Menezes AR, Lavie CJ, Milani RV, Forman DE, King M, et al. (2014) Cardiac rehabilitation in the United States. Prog Cardiovasc Dis 56: 522-529. [Crossref]

21. Anderson L Thompson DR, Oldridge N, Zwisler AD, Rees K, et al. (2016) Exercisebased cardiac rehabilitation for coronary heart disease. Cochrane Database Syst Rev 5: 1-9. [Crossref]

Copyright: (C2020 Auchi EE. This is an open-access article distributed under the terms of the Creative Commons Attribution License, which permits unrestricted use, distribution, and reproduction in any medium, provided the original author and source are credited. 